\title{
COMPARATIVE STUDY BETWEEN 2 TYPES OF PROLOTHERAPY IN TREATMENT OF CHRONIC RECURRENT TEMPOROMANDIBULAR JOINT DISLOCATION
}

\author{
Nahla A. Khamis ${ }^{1} B D S$, Saeeda M. Osman ${ }^{2} P h D$, Nevein S. Mohamed ${ }^{2} P h D$
}

\begin{abstract}
INTRODUCTION: Temporomandibular Joint (TMJ) dislocation when condyles travel anterior to articular eminence. It may be reducible or irreducible. Chronic recurrent TMJ dislocation was treated by surgical and nonsurgical methods. Minimally invasive methods include injection of sclerosing agents intra-articular and extra-capsular or botulinum toxin to the surrounding muscles. Prolotherapy is a method of strengthening lax ligaments by injecting various types of sclerosing or proliferant solutions such as ethanolamine oleate $5 \%$, autologus blood and others. It is also known as "ligament sclerotherapy" or "regenerative injection therapy"

OBJECTIVES: the study aimed to compare 2 types of prolotherapy (autologous blood \& ethanolamine Oleate sclerosing agent) injection in treatment of chronic recurrent temporomandibular joint dislocation.

MATERIALS AND METHODS: : this study was parallel, controlled, randomized, clinical trial. The study was conducted at Oral and Maxillofacial Surgery Department, Faculty of Dentistry, Alexandria University, Egypt. Thirty patients with chronic recurrent temporomandibular joint dislocation were chosen with certain inclusion and exclusion criteria. Fifteen participants were injected with ethanolamine oleate compared with fifteen patients were injected with autologous blood and were followed-up for six months. The participated patients were assessed at the pre- and post-treatment stages by evaluating pain and mandibular range of motion clinically and radiographically using Magnatic Resonance Imaging (MRI) to evaluate condyle-articular eminence relation in opening and closing mouth.

RESULTS: There was no significant difference between both prolotherapies in treating chronic recurrent temporomandibular joint dislocation. CONCLUSIONS: Ethanolamine oleate and autologus blood injection are simple, safe and cost-effective treatment for management of chronic recurrent temporomandibular joint dislocation.

KEYWORDS: Prolotherapy, Temporomandibular Joint dislocation, autologous blood, ethanolamine oleate.
\end{abstract}

1-B.D.S, Oral and Maxillofacial Surgery Department, Faculty of Dentistry, Alexandria University, Alexandria, Egypt.

2-Professor of Oral and Maxillofacial Surgery Department, Faculty of Dentistry, Alexandria University, Alexandria, Egypt.

3-Professor of Oral and Maxillofacial Surgery Department, Faculty of Dentistry, Alexandria University, Alexandria, Egypt.

Corresponding author:

E-mail: nony_omar@hotmail.com

\section{INTRODUCTION}

Temporomandibular joint (TMJ) dislocation occurs when one or both mandibular condyles travel anterior to the articular eminence and remains there. It may be reducible when it returns spontaneously to the glenoid cavity, or irreducible when one or two condyles remain dislocated. In this position, the mouth remains open due to the action of the elevator muscles with or without lateral deviation, depending on whether the dislocation is unilateral or bilateral (1).

Acute temporomandibular joint dislocation is usually managed by manually pressing the mandible downwards and then pushing it back upwards in an attempt to try to relocate the condyle in the glenoid fossa (2). If the condyle continues to dislocate several times, it is described as chronic recurrent TMJ dislocation. Chronic recurrent TMJ dislocation may occur as a result of everyday activities such as yawning and laughing. Also it may occur after excessive mouth opening during dental treatment and general anesthesia procedures. Some authors have mentioned that this condition is prevalent with TMJ internal derangement (3).

The pathogenesis of chronic recurrent TMJ dislocation is attributed to a combination of factors including laxity of the TMJ ligaments, weakness of the TMJ capsule, an unusual eminence size or projection, muscle hyperactivity or spasms, trauma, and abnormal chewing movements that do not allow the condyle to translate back (4).

Recurrent dislocation of the TMJ may cause injury to the disc, capsule, and ligaments leading to progressive TMJ internal derangement (3).

Different surgical and nonsurgical methods have been used for the treatment of TMJ hypermobility. The conservative methods include physiotherapy, occlusal splints and avoiding activities that cause large mouth opening (5-7).

Conservative treatment methods are not always successful. Therefore, multiple surgical procedures were developed including capsular plication, (8) reduction or augmentation of the articular eminence, (9) temporalis tendon scarification, (10) lateral pterygoid myotomy (11) and condylectomy (12).

Minimally invasive methods include injections of sclerosing agents intra-articularly and extra-capsularly or injections of botulinum toxin to the surrounding muscles (13-15).

Prolotherapy is a method of strengthening lax ligaments by injecting various types of sclerosing or proliferant solutions. It is also known as "sclerotheraphy", "proliferative injection therapy", "regenerative injection 
therapy" or "ligament sclerotherapy". Autologous blood and ethanolamine oleate are used as proliferant solutions $(16,17)$.

Autologous blood injection in the TMJ for the treatment of hypermobility is a simple technique (18). It creates an inflammatory reaction in the artificially created wound which induces fibrosis, formation of adhesions and scarring in the joint and in the surrounding soft tissue with immobilization of the mandible avoiding early stretching of the newly formed fibrous tissue. This method proved to be successful in $80 \%$ of patients with recurrent dislocation (1).

The sclerosing agents most widely used are 5\% Sodium Morruhate, 1\% Polidocal, Sodium Tetradecyl Sulfate, Absolute Alcohol and 5\% Ethanol amine Oleate (19).

Ethanolamine Oleate (EO) is a sclerosing agent which has been approved by the Food and Drug Administration (FDA) for the treatment of varicose veins and esophageal varices. It is a minimally invasive, simple and effective technique. It is less likely to cause allergic reactions than sodium morrhuate or sodium tetradecyl sulfate (20).

Ethanolamine Oleate is a salt of an unsaturated fatty acid that acts as a sclerosant (21). When EO is injected intravenously, it causes irritation in the endothelial intimal layer of the vein producing an inflammatory response culminating in fibrosis of the vessel wall and possibly vein occlusion. It can diffuse through the venous wall producing an extravascular inflammatory reaction and thus may induce venous sclerosis (22).

To our knowledge, there is no sufficient data about the effect of these prolotherapies in treating chronic recurrent TMJ dislocation. Therefore, this study assessed the difference between ethanolamine oleate and autologous blood injection in treatment of chronic recurrent TMJ dislocation.

\section{MATERIALS AND METHODS}

\section{Study design}

The study was performed as an investigator blinded randomized, controlled study. Thirty patients with a confirmed diagnosis of chronic recurrent TMJ dislocation were selected in this study from the outpatient clinic of the Oral and Maxillofacial surgery Department, Faculty of Dentistry, Alexandria University.

\section{Patients were divided into two equal groups}

Group A: Fifteen patients were treated with a sclerosing agent (Ethanolamine oleate) injection .

Group B: Fifteen patients were treated with autologous blood injection.

\section{Participants}

Patient selection was based on certain inclusion and exclusion criteria. The inclusion criteria stated that patient must be diagnosed clinically and radiographically by Magnetic Resonance Imaging (MRI) with chronic recurrent temporomandibular joint dislocation. Dislocation was unilateral or bilateral and its episode ranged from one time to several times per week. Patients were able to self reduce the dislocation whereas others required assistance. The exclusion criteria stated that patients must not have systemic diseases, previous TMJ surgery, shallow eminence or joint fractures.

All participants were medically healthy adult patients (ASA classification I-II). Patients were fully informed about the operation and the risks of the operation. The study was approved by Ethics committee in Faculty of Dentistry,
Alexandria University. Informed consent was obtained from each patient prior to participation in this study in accordance with the regulation of the Ethics committee in Faculty of Dentistry, Alexandria University.

\section{Materials:}

\section{Ethanolamine oleate (EO):}

EO contains approximately 50mg ethanolamine oleate per $\mathrm{ml}$ and benzyl alcohol $2 \%$ by volume which is used as a preservative. EO is a synthetic mixture of ethanolamine and oleic acid with an empirical formula of C20H41NO3. (20)

\section{Pre-operative phase}

Clinical examination: We assessed patients using subjective and objective evaluation methods. The subjective evaluation performed by evaluation of average duration of symptoms, number of episodes of dislocation, patients ablity to self reduce the dislocation or require assistance and bite was comfortable or not. The objective evaluation method performed by measuring mandibular range of motion, determination of TMJ pain during various mandibular movements and at rest using visual analoge scale (VAS),(25) presence of joint noise on palpation and tenderness of masticatory muscles.

Radiographic examination: using MRI to evaluate disccondyle relation, intra-articular adhesions, synovial fluid content, osseous abnormalities of the condyle and temporal eminence and condyle -articular eminence relation in opening and closing mouth.

Occlusal splint (hard mandibular full vacuum splints 2 $\mathrm{mm}$ in thickness) was used two weeks prior to the injection then for another three weeks post-operative.

\section{Operative phase}

The joint was palpated during mandibular movements to locate the condyle and the mandibular fossa. The ear and pre-auricular skin over the TMJ were cleaned with Povidone-iodine solution u.s.p 10\% w/v (Betadine, NILE Company for Pharmaceutical and Chemical Industries, Cairo, Egypt) and the area was isolated with sterile towels.

Two points were then marked over the articular fossa and eminence, $1 \mathrm{~cm}$ in front of the tragus along with the lateral canthal-tragus line and $2 \mathrm{~mm}$ below the tragus. The subcutaneous tissues lateral to the joint were infiltrated with a local anaesthetic solution Mepevacaine HCL 2\% (Mepevacaine L of Alexandria Co. for Pharmaceuticals, Alexandria, Egypt) and epinephrine as Levonordefrin $1: 200,000$ in a $1.8 \mathrm{ml}$ carpule, then the auriculotemporal nerve was blocked by injection of the anaesthetic solution posterior to the condylar neck.

For the first group, $5 \mathrm{ml}$ of ethanolamine oleate $5 \%$ (Egyptian International Pharmaceutical Industries Co., 10th of Ramadan City, Egypt) (26) was injected once, $2 \mathrm{ml}$ was injected into the superior joint space and needle was moved outward for $1 \mathrm{~cm}$ and additional $3 \mathrm{ml}$ of it was injected in the pericapsular tissue Fig.(1,2).

For the second group, autologous blood was withdrawn from the patient's antecubital fossa about $5 \mathrm{ml}$. Fig.(3). Only $2 \mathrm{ml}$ of blood was injected once into the superior joint space and needle was moved outward for $1 \mathrm{~cm}$ and additional 3 $\mathrm{ml}$ of blood was injected in the pericapsular tissue. Fig.(2) 


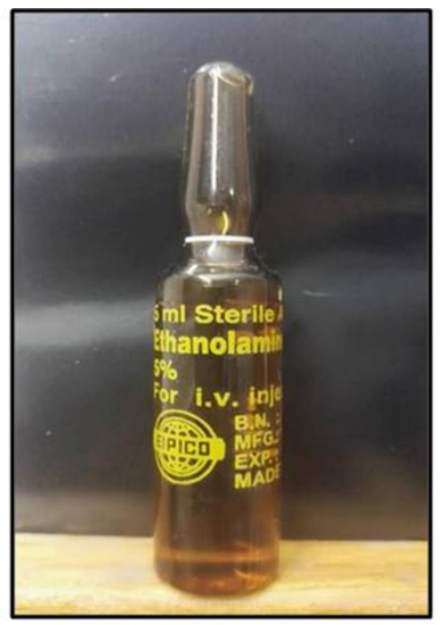

Figure (1): Ethanolamine Oleate 5\%.

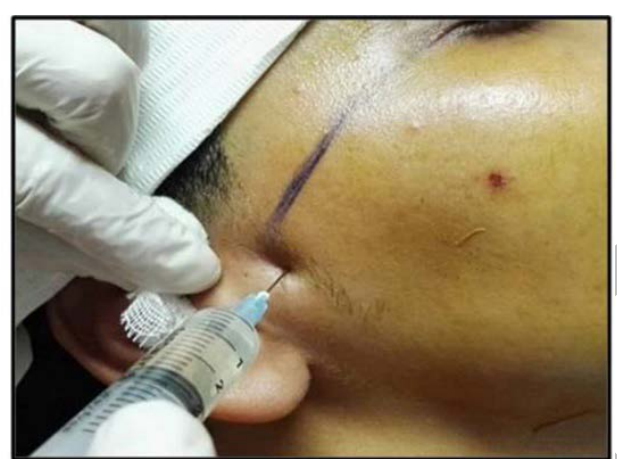

Figure (2): Injection site for both prolotherapies.

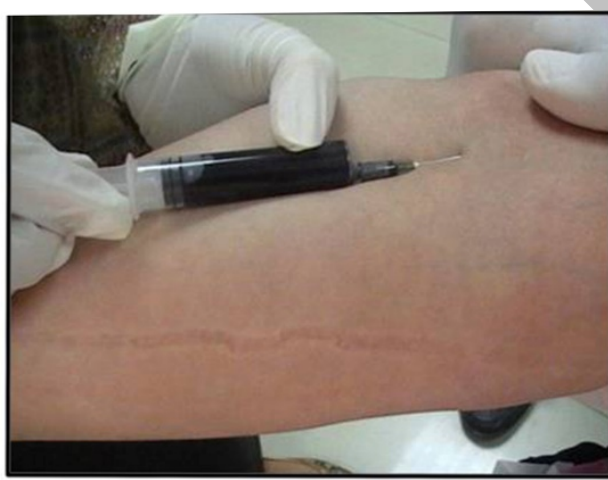

Figure (3): Blood withdrawal procedure using median cubital vien.

\section{Post-operative phase}

Patients were instructed to restrict their mouth opening and to eat only soft foods for 21 days, apply elastic head bandage for the first three weeks Fig.(4), wear occlusal splints at night Fig.(5) and take their medications regularly (875 mg of amoxicillin: $125 \mathrm{mg}$ clavulanic acid (Augmentin, GlaxoSmithKline, UK) 1gm/12hours orally for 5 days, Anti-edematous agent, in the form $\alpha$ chymotrypsin ampoules ( $\alpha$ - chymotrypsin, Leurquin, France) was prescribed once daily for 5 days. Analgesic: diclofenac potassium (Cataflam, Novartis, Switzerland) (50 $\mathrm{mg} / 8$ hours) prescribed for 5 days). Jaw rehabilitation five times after three weeks post-operatively.

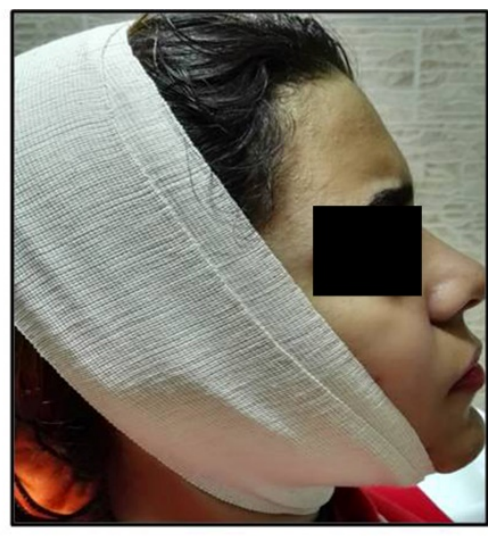

Figure (4): Postoperative elastic head bandage.

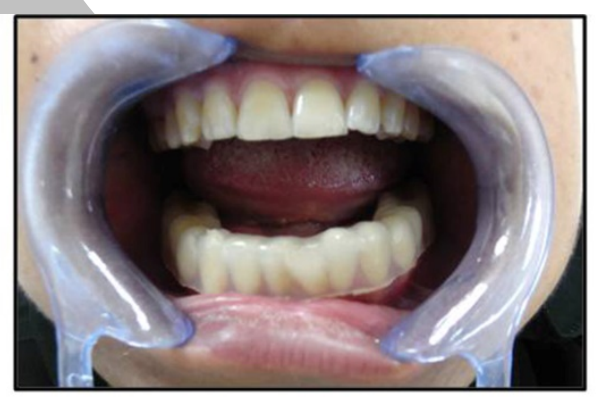

Figure (5): Mandibular occlusal splint.

Follow-up phase

The clinical assessments were done five times for each patient, one time at pre-treatment period and four times post-treatment (after two weeks, four weeks, three months and six months). These included pain intensity, joint sound, regional tenderness, masticatory muscle tenderness, mandibular range of motion and recurrence of dislocation. The results obtained from this study were categorized in two axes. Firstly; statistical analysis was done between the two treatment groups at pre- and post-treatment assessments. The pre-treatment analysis aimed at confirming similar conditions and scores before the initiation of the treatment and also to predict possible variations in the therapeutic outcomes in both study groups. Analysis was done within each group separately at pre- and post-treatment phases for the evaluation of progression or regression of the signs and symptoms.

All of the patients in both groups were scanned 3 months after the therapy with a $1.5 \mathrm{~T}$ Magnetic Resonance Imaging (MRI) scanner (Achieva; Philips Medical Systems, Best, The Netherlands) using a multichannel head coil. In each MRI evaluation, the position of the condyle in relation to the glenoid fossa, disc-condyle relation and the temporomandibular joint surfaces were noted for any changes.

\section{Statistical analysis (23)}

Statistical analysis was done using IBM SPSS software package version 20.0. (Armonk, NY: IBM Corp) (24). The Kolmogorov- Smirnov, Shapiro and D'agstino tests were used to verify the normality of distribution of variables, Comparisons between groups for categorical variables were assessed using Chi-square test (Fisher or Monte Carlo), Comparisons between the different stages for categorical variables were assessed using McNemar-Bowker and Marginal Homogeneity Test. Student t-test was used to compare two groups for normally distributed quantitative variables, while ANOVA with repeated measures and Post 
Hoc test (Bonferroni adjusted) were assessed for comparison between different periods. Mann Whitney test was used to compare between two groups for abnormally distributed quantitative variables. Significance of the obtained results was judged at the 5\% level.

\section{RESULTS}

\section{Demographic data}

The patients were divided into two groups each consisting of fifteen patients of both sex in each group. In group A, $46.7 \%$ male and $53.3 \%$ female. In group B, $6.7 \%$ male and 93.3\% female.

Their age ranged from 17 to 40 years old with Mean \pm $\mathrm{SD}$ in group A $23.73 \pm 4.62$ and $24.40 \pm 6.63$ in group $\mathrm{B}$.

Bilateral cases were $70 \%$ in group A, while $90 \%$ in group B. Unilateral cases were $30 \%$ in group A, while $10 \%$ in group B.

\section{Clinical analysis}

After the clinical follow up at the end of the follow-up period (6 months), most of patients were satisfied with the results achieved. They had stable joints, could chew normally and required no further treatment. Both groups were compared in their objective and subjective findings pre- and post-operative assessments.

The statistical analysis of the right, Lateral \& protrusive movements of the jaws had shown better improvements of group B compared to group A patients and the statistical analysis of MIO had shown better improvements of group A compared to group B. (Table 1, 2,3)

There was increasing evidence that the subjective symptoms and objective measurements improved during follow-up appointments in both groups with complete ablation of muscle tenderness. $100 \%$ no recurrence of dislocation in group A while $13.3 \%$ recurrence in group B.

All clinical parameters in both groups were statistically significant when compared to the pre-operative values within the same group at all stages of follow up period except regional tenderness for group $A$ the results were insignificant at 4weeks follow-up and at group B at 2 weeks and PM in group B at 6 months. (Table $\mathbf{1}, \mathbf{2}, \mathbf{3}$ )

Comparing the two studied groups, there was no significance in all parameters at all stages of the follow up period except pain intensity preoperative and 2 weeks, TMJ tenderness at 2, 4 weeks, masticatory muscle Tenderness preoperatively, all LLM except 6 months and protrusive movement 2 weeks, 3, 6 months.(Table 1, 2, 3)

\section{Radiographic analysis}

All of the patients in both groups were scanned before and 3 months after the therapy with Magnetic Resonance Imaging (MRI). Both of the joints were imaged in each patient. In pre-injection MRI evaluation, patients had unilateral or bilateral condyles anterior to the eminence with their mouths in the open position with no evidence of secondary bone changes or soft tissue masses and no osteoarthritis in any patients. (Figs.6 [A,B]). Three months after the injection, MRIs revealed (1) Slight anterior disc displacement. (2) Mild degenerative changes of both meniscus without tear or dislocation. (3) Normal smooth articular surface of the condylar fossa. (4) Normal mandibular condyle bony texture and articular surface. (Figs.6 [C,D]).
Table (1): Comparison between the two studied groups according to MIO, protrusive movement, lateral movement right and left.

\begin{tabular}{|c|c|c|c|c|}
\hline & $\begin{array}{c}\text { Group A } \\
(n=15)\end{array}$ & $\begin{array}{c}\text { Group B } \\
(n=15)\end{array}$ & $\mathbf{t}$ & $\mathbf{p}$ \\
\hline \multicolumn{5}{|l|}{ MIO (mm) } \\
\hline Preoperative & $35.57 \pm 11.43$ & $30.46 \pm 11.38$ & 1.228 & 0.230 \\
\hline 2 weeks & $26.51^{\#} \pm 6.25$ & $30.79 \pm 10.57$ & 1.350 & 0.188 \\
\hline 4 weeks & $34.23 \pm 11.40$ & $34.35 \pm 7.37$ & 0.034 & 0.973 \\
\hline 3 Months & $37.93 \pm 6.06$ & $33.47 \pm 7.16$ & 1.842 & 0.076 \\
\hline 6 Months & $38.09 \pm 6.23$ & $33.62 \pm 7.21$ & 1.818 & 0.080 \\
\hline \multicolumn{5}{|c|}{$\begin{array}{c}\text { Protrusive movement } \\
\text { (mm) }\end{array}$} \\
\hline Preoperative & $4.31 \pm 0.75$ & $4.17 \pm 2.17$ & 0.236 & 0.817 \\
\hline 2 weeks & $2.97^{\#} \pm 0.56$ & $3.67 \pm 1.16$ & $2.113^{*}$ & $0.047^{*}$ \\
\hline 4 weeks & $4.0 \pm 1.25$ & $4.10 \pm 1.73$ & 0.182 & 0.857 \\
\hline 3 Months & $5.54 \pm 2.09$ & $3.93 \pm 1.24$ & $2.571^{*}$ & $0.017^{*}$ \\
\hline 6 Months & $5.55 \pm 2.12$ & $3.94 \pm 1.26$ & $2.524^{*}$ & $0.019^{*}$ \\
\hline \multicolumn{5}{|c|}{$\begin{array}{l}\text { Lateral Movement } \\
\text { (Right) (mm) }\end{array}$} \\
\hline 2 weeks & $3.70 \pm 0.42$ & $4.75 \pm 2.0$ & 1.991 & 0.065 \\
\hline 4 weeks & $3.80 \pm 1.14$ & $4.75 \pm 1.71$ & 1.783 & 0.085 \\
\hline 3 Months & $4.64 \pm 2.37$ & $3.55 \pm 1.60$ & 1.481 & 0.151 \\
\hline 6 Months & $4.66 \pm 2.40$ & $3.96 \pm 1.85$ & 0.894 & 0.379 \\
\hline \multicolumn{5}{|c|}{$\begin{array}{c}\text { Lateral Movement (Left) } \\
\text { (mm) }\end{array}$} \\
\hline Preoperative & $5.97 \pm 0.67$ & $4.01 \pm 0.88$ & $6.848^{*}$ & $<0.001^{*}$ \\
\hline 2 weeks & $4.67 \pm 2.99$ & $4.25 \pm 1.59$ & 0.480 & 0.636 \\
\hline 4 weeks & $5.87 \pm 2.01$ & $4.59 \pm 0.86$ & $2.257^{*}$ & $0.036^{*}$ \\
\hline 3 Months & $6.38 \pm 1.95$ & $4.41^{\#} \pm 0.86$ & $3.578^{*}$ & $0.002^{*}$ \\
\hline 6 Months & $6.36 \pm 1.93$ & $4.41^{\#} \pm 0.83$ & $3.602^{*}$ & $0.002^{*}$ \\
\hline
\end{tabular}

$\mathrm{t}, \mathrm{p}$ : $\mathrm{t}$ and $\mathrm{p}$ values for Student t-test for comparing between the two groups

\#: Statistically significant at $\mathrm{p} \leq 0.05$ for comparing between Preoperative and each other period

$*$ : Statistically significant at $p \leq 0.05$

Group A: EO injection

Group B: Autologous blood injection

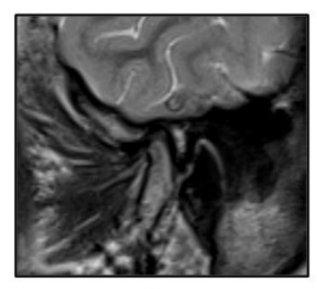

$\mathbf{A}$

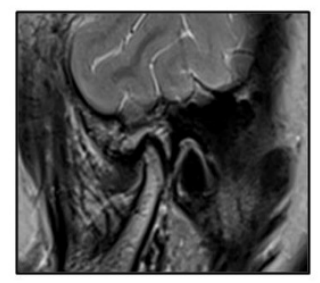

C

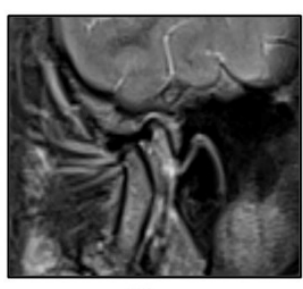

B

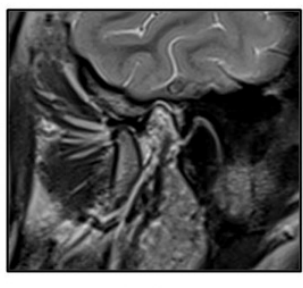

D
Figure (6): MRI images of the left TMJ. A. close- mouth position before injection. B. open- mouth position before injection. C. close -mouth position after injection. D. open-mouth position after injection. 
Table (2): Comparison between the two studied groups according to pain intensity (VAS).

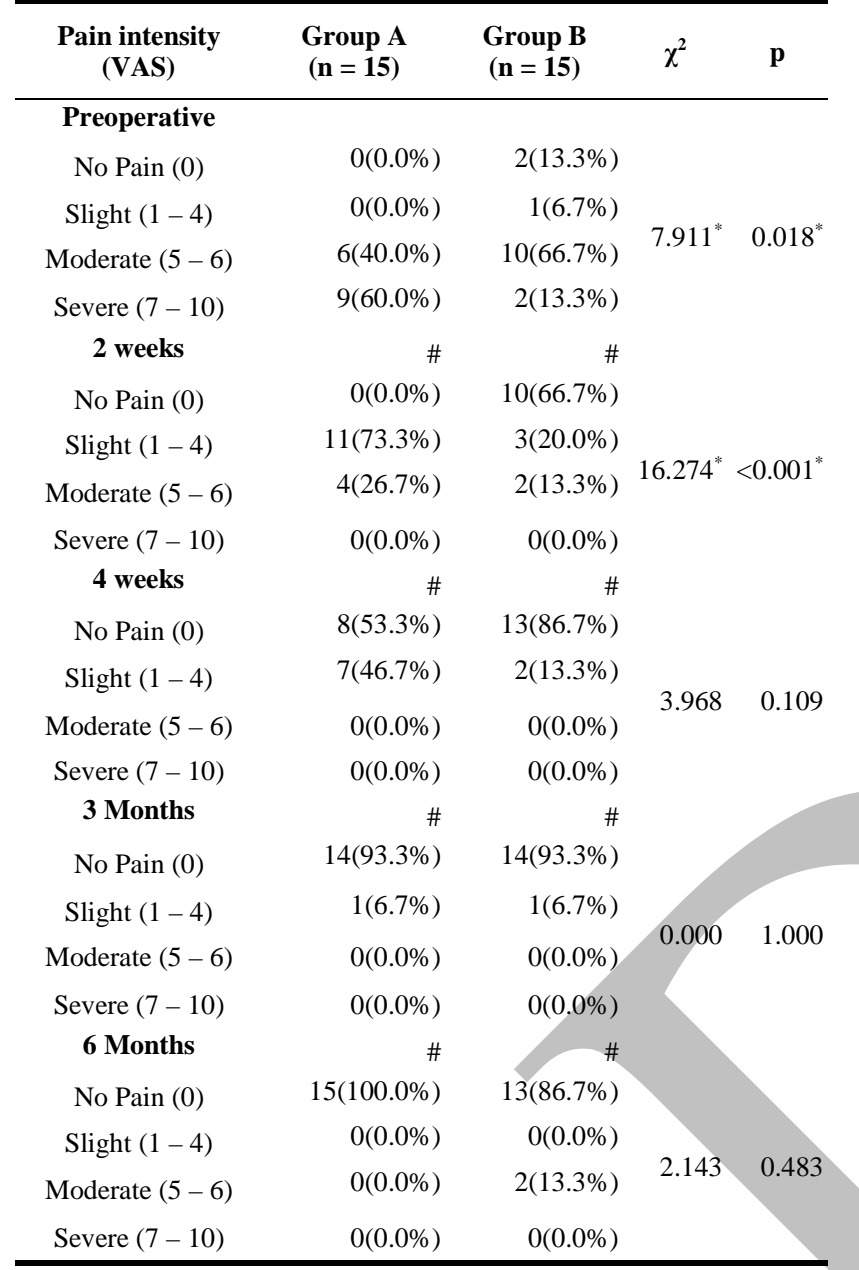

${ }^{2}, \mathrm{p}: \chi^{2}$ and $\mathrm{p}$ values for Chi square test for comparing between the two groups

\#: Statistically significant at $\mathrm{p} \leq 0.05$ for comparing between Preoperative and each other periods

$*$ : Statistically significant at $\mathrm{p} \leq 0.05$

Group A: EO injection

Group B: Autologous blood injection

Table (3): Comparison between the two studied groups according to regional tenderness, joint sound, masticatory muscle tenderness and recurrent dislocation.

\begin{tabular}{ccccc}
\hline & $\begin{array}{c}\text { Group A } \\
\text { (n= 15) }\end{array}$ & $\begin{array}{c}\text { Group B } \\
(\mathbf{n = 1 5 )}\end{array}$ & $\chi^{2}$ & $\mathbf{p}$ \\
\hline Regional tenderness & & & & \\
Pre-operative & $15(100.0 \%)$ & $13(86.7 \%)$ & 2.143 & 0.483 \\
2 weeks & $15(100.0 \%)$ & $8(53.3 \%)$ & $9.130^{*}$ & $0.006^{*}$ \\
4 weeks & $11(73.3 \%)$ & $\# 5(33.3 \%)$ & $4.821^{*}$ & $0.028^{*}$ \\
3 Months & $\# 2(13.3 \%)$ & $\# 3(20.0 \%)$ & 0.240 & 1.000 \\
6 Months & $\# 0(0.0 \%)$ & $\# 2(13.3 \%)$ & 2.143 & 0.483 \\
Joint Sound & & & & \\
Pre-operative & $15(100.0 \%)$ & $14(93.3 \%)$ & 1.034 & 1.000 \\
2 weeks & $\# 5(33.3 \%)$ & $\# 2(13.3 \%)$ & 1.677 & 0.390 \\
4 weeks & $\# 0(0.0 \%)$ & $\# 0(0.0 \%)$ & - & - \\
3 Months & $\# 0(0.0 \%)$ & $\# 1(6.7 \%)$ & 1.034 & 1.000 \\
6 Months & $\# 0(0.0 \%)$ & $\# 2(13.3 \%)$ & 2.143 & 0.483 \\
Masticatory muscle & & & & \\
tenderness & & & & \\
Pre-operative & $15(100.0 \%)$ & $8(53.3 \%)$ & $9.130^{*}$ & $0.006 *$ \\
2 weeks & $\# 2(13.3 \%)$ & $\# 0(0.0 \%)$ & 2.143 & 0.483 \\
4 weeks & $\# 1(6.7 \%)$ & $\# 0(0.0 \%)$ & 1.034 & 1.000 \\
3 Months & $\# 0(0.0 \%)$ & $\# 1(6.7 \%)$ & 1.034 & 1.000 \\
6 Months & $\# 0(0.0 \%)$ & $\# 2(13.3 \%)$ & 2.143 & 0.483 \\
Recurrent dislocation & $0(0.0 \%)$ & $2(13.3 \%)$ & 2.143 & 0.483 \\
\hline
\end{tabular}

$\chi^{2}, \mathrm{p}: \chi^{2}$ and $\mathrm{p}$ values for Chi square test for comparing between the two groups
\#: Statistically significant at $p \leq 0.05$ for comparing between Preoperative and each other periods

*: Statistically significant at $\mathrm{p} \leq 0.05$

Group A: EO injection

Group B: Autologous blood injection

\section{DISCUSSION}

Many sclerosants had been tried for the treatment of various lesions such as lymphangioma, vascular malformation, renal and hepatic cysts and so on. The TMJ is different from lesions in which only destruction is needed. The structure of the TMJ must not be destroyed: all that is required is restriction of the sliding of the condyle over the articular eminence. Appropriate scar contraction is desirable.(15)

Many researchers studying Ethanolamine Oleate treatments highlighted the high efficacy in endoscopic injection sclerotherapy of esophageal varices and recently hemangiomas and vascular malformations. $(21,27)$ In our study, this was the first time to inject EO in TMJ or any other joint in the body. So there were no exact points to compare with the results in this current study.

Our gained results had shown that: group B patients decreased in MIO more than group A patients in the first month then after 6 months group B decreased by $15.47 \pm 5.31$ while group A patients decreased by $12.21 \pm 3.72 \%$ so finally group B decreased in MIO more than group A and this difference is not statistically significant.

In 6 months follow-up period, the decrease in mandibular range of motion including MIO, RLM, LLM and PM in the current study after injection of EO confirmed fibrous tissue formation. This was in agreement with Choi et al (28) as the microscopic findings after 1 month revealed inflammatory organization, perivascular fibrosis or inflammatory cell infiltration into the surrounding muscles or connective tissues in the treatment of craniofacial cavernous venous malformations (Hemangioma and Vascular malformation). Also this was parallel with Ahmed 2016 (27) in which fibrosis of endothelium of supplying blood vessels of peripheral giant cell granuloma after EO sclerotherapy.

The current study showed no postoperative complications and no episodes of recurrence after EO injection. These results were consistent with Brasil da Silva et al. 2014 (22) who reported no visible scars or compromise esthetics or normal function and there was no evidence of recurrence in the treatment of Oral capillary hemangioma with EO sclerotherapy. Only one patient had superficial ulceration which remained asymptomatic and healed without specific treatment. In agreement with Das and Hoque (29) which reported no recurrence of the injected patients with EO in treatment of venous malformations. All patients experienced pain and swelling in a variable degree for short duration but with light contrast as skin sloughed out in 4 patients which were healed spontaneously.

Postoperative pain and swelling noticed after EO injection in our study which subsided within first week. These results were consistent with Hong et al 2010 (21) in which the only complication was transient pain that subsided within 1 week in two patients. None of the patients developed scarring. Also these results were parallel with Pradhan and Rahaman(19) 2011 in which minor complications subsided in 3- 4 days in treating Benign Oral and Perioral Vascular Lesions with EO sclerotherapy. 
Our study reported high success rate of sclerotherapy with EO (100\%) in chronic TMJ dislocation. These results were parallel to Yamamoto et al (30) who reported that sclerotherapy with EO was a safe, effective, well-tolerated treatment for symptomatic hepatic or renal cysts. The mean reduction rate at 3 months after therapy was 93\%.Also were parallel to Hong et al 2010 (21) in which complete remission was achieved in $95 \%$ of the reactive vascular lesions after EO injection and others (27,28,31).

The principle behind $\mathrm{ABI}$ is to restrict mandibular movements by inducing fibrosis in upper joint space, pericapsular tissues or both by injecting blood into TMJ (32).

When focus on the number of blood injections used, the results of our study showed restriction of joint movement using one injection of autologous blood. It could be explained that the single dose of the injected blood is quite sufficient to prevent the TMJ dislocation. Whereas Schulz 1973(33) achieved the same results using several injections of autologous blood. Jacobi-Hermanns and Tetsch in 1981(34) were in agreement with the current study. Uneventful healing was reported in all patients who received only one injection.

In current study, the mean MIO was $33.13 \pm 9.50 \mathrm{~mm}$ preoperatively and $28.24 \pm 8.78 \mathrm{~mm}$ postoperatively after ABI. Such results of MIO were parallel with Vasconcelos et al (35) in spite of the invasive technique (eminectomy) that they did who reported that the mean MIO preoperatively was $48.4+/-8.5 \mathrm{~mm}$ and postoperatively was $41.3+/-5.0 \mathrm{~mm}$. We achieved the same results by the noninvasive one (Table 1).

Our results contradicted with Anjum et al (36) as there was no statistically significant decrease in mouth opening. This difference in results might be due to ABI was only used into superior joint space so no decrease in mouth opening occurred. Also hard chewable diet and life patron of his study patients in whom reduction in mouth opening didn't occurred without physiotherapy.

According to TMJ sound, all the cases complained from clicking preoperatively and by the end of follow up period, $86.7 \%$ had no TMJ sound after single ABI but $13.3 \%$ had clicking sound. This was in agreement with Triantafillidou al (37) who reported that the number of injected blood depended on remission of sounds. $13.3 \%$ might be due to they need a second injection.

All of the patients in group B tolerated the procedure without serious complications. There were no cases of facial nerve weakness, no deviation in mouth opening and no scars. Most of the patients generally reported pain and swelling which were controlled by postoperative medications and relieved within the first week. These results were in agreement with Bayoumi et al (38).

The results of the present study showed a significant reduction in pain intensity and joint sound in both groups throughout the follow-up period $(\mathrm{p} \leq 0.05)$. Although the decreased amount of pain and sound was greater in group A. When comparing both groups, the difference in pain intensity and joint sound was statistically insignificant ( $\mathrm{p}>0.05)$.

The results of the present study showed that all patients in both groups had regional (joint and muscle) tenderness preoperatively which decreased gradually along the study period. No patients at group A had tenderness at the end of the follow up period. In group B, 13.3\% of the patients had tenderness at the end of the follow up period.

Although in regional tenderness, there was statistically significant difference between the two groups after 2 and 4weeks $(p<0.05)$, there was no statistically significant difference between the two groups preoperatively and during the follow- up period at 3 and 6 months ( $>0.05$ ).

In masticatory muscle tenderness, there was no statistically significant difference between the two groups in all periods ( $>0.05$ ) except preoperatively, there was statistically significant difference $(\mathrm{p}<0.05)$.

The differences between the two groups were statistically insignificant throughout the postoperative period $(\mathrm{P}>0.05)$, although group A showed superior results. This result might be due to insufficient sample size to represent the whole population.

In our study, with the exception of some tenderness over the treated TMJ in the immediate postoperative phase, there were no complications experienced by any of the patients postoperatively.

MRI interpretations between both groups in preoperative and 3month after treatment had shown no structural changes that described the prevention of the dislocations such as fibrosis. However, fibrotic changes had been revealed by histological examination of TMJs with EO injection as Matsumotoa et al (39) who found fibrous tissue confined to the posterior slope of the articular eminence and disk surface by his the arthroscopic finding.

In our knowledge, this was the first study that evaluated the effect of the ethanolamine oleate and autologous blood injection procedure by MRI in treating chronic recurrent temporomandibular joint dislocation.

\section{CONCLUSION}

Both types of prolotherapy were simple, safe and costeffective treatment modalities for management of chronic recurrent TMJ dislocation.

\section{CONFLICT OF INTEREST}

The authors declare that they have no conflicts of interest.

\section{REFERENCES}

1. Machon V, Abramowicz S, Paska J, Dolwick MF. Autologous blood injection for the treatment of recurrent TMJ dislocation. J Oral Maxillofac Surg. 2009;67:114-9.

2. Çandrl C, Yüce S, Yldrm S, Sert H. Histopathologic Evaluation of Autologous Blood Injection to the Temporomandibular Joint. J Craniofac Surg. 2011;22:2202-4.

3. Nitzan DW. Temporomandibular joint 'open lock' versus condylar dislocation. Signs and symptoms, imaging, treatment and pathogenesis. J Oral Maxillofac Surg. 2002;60:506-10.

4. Undt G, Kermer C, Rasse M. Treatment of recurrent mandibular dislocation, Part II: Eminectomy. Int J Oral Maxillofac Surg. 1997;26:98.

5. Oztan HY, Ulusal BG, Turegun M, Deveci M. Titanium screw implantation to the articular eminence for the treatment of chronic recurrent dislocation of the temporomandibular joint. Int $\mathrm{J}$ Oral Maxillofac Surg. 2005;34:921-3.

6. Schiffman EL, Look JO, Hodges JS, Swift JQ, Decker KL, Hathaway KM, et al. Randomized effectiveness study of 
four treatment strategies for TMJ closed lock. J Dent Res. 2007;86:58-63.

7. Babada M, Sahin M, Görgün S. Pre and posttreatment analysis of clinical symptoms of patients with temporomandibular disorders. Quintessence Int. 2004;35:811-4.

8. MacFarlane WI. Recurrent dislocation of themandible: treatment of seven cases by a simple surgical method. Br J Oral Surg. 1977;14:227-9.

9. Puelacher WC, Waldhart E. Miniplate eminoplasty: a new surgical treatment for TMJ dislocation. J Craniomaxillofac Surg. 1993;21:176-8.

10. Gould JF. Shortening of the temporalis tendon for hypermobility of the temporomandibular joint. J Oral Maxillofac Surg. 1978;36:781-3.

11. Miller GA, Murphy EJ. External pterygoid myotomy for recurrent mandibular dislocation. Review of the literature and report of a case. Oral Surg Oral Med Oral Pathol. 1976;42:705-16.

12. James P. The surgical treatment of mandibular joint disorder. Ann Roy Coll Surg. 1971;49:495-505.

13. Aquilina P, Vickers R, McKellar G. Reduction of a chronic bilateral temporomandibular joint dislocation with intermaxillary fixation and botulinum toxin A. Br J Oral Maxillofac Surg. 2004;42:272-3.

14. Martinez-Perez D, Garcia Ruiz-Espiga P. Recurrent temporomandibular joint dislocation treated with botulinum toxin: report of 3 cases. J Oral Maxillofac Surg 2004;62:244-6.

15. Matsushita K, Abe T, Fujiwara T. OK-432 (Picibanil) sclerotherapy for recurrent dislocation of the temporomandibular joint in elderly edentulous patients. Case reports. Br J Oral Maxillofac Surg. 2007;45:511-3.

16. Refai H, Altahhan O, Elsharkawy R. The efficacy of dextrose prolotherapy for temporomandibular joint hypermobility: a preliminary prospective, randomized, double-blind, placebo-controlled clinical trial. J Oral Maxillofac Surg. 2011;69:2962-70.

17. Kumar AV, Jaishankar HP, Kavitha AP, Naik PR. Prolotherapy: A new hope for TMJ pain. Indian J Pain. 2013;27:119-165.

18. Emad T. Daif, Autologous blood injection as a new treatment modality for chronic recurrent temporomandibular joint dislocation. Oral Surg Oral Med Oral Pathol Oral Radiol Endod. 2010;109:31-6.

19. Pradhan L, Rahman QB. Effectiveness of Sclerotherapy with Ethanol Amine Oleate in Benign Oral and Perioral Vascular Lesions. BSMMU J. 2011;4:110-5.

20. Kiripolsky MG. More on Ethanolamine Oleate as a vascular sclerosant. Dermatol Surg. 2010;36:1153-4.

21. Hong SK, Lee HJ, Seo JK, Lee D, Hwang SW, Sung HS. Reactive Vascular Lesions Treated Using Ethanolamine Oleate Sclerotherapy. Dermatol Surg. 2010;36:1148-52.

22. Da Silva WB, Ribeiro AL, de Menezes SA, de Jesus Viana Pinheiro J, de Melo Alves-Junior S. Oral capillary hemangioma: a clinical protocol of diagnosis and treatment in adults. Oral Maxillofac Surg. 2014;18:431-7.

23. Kotz S, Balakrishnan N, Read CB, Vidakovic B. Encyclopedia of statistical sciences. 2nd ed. Hoboken, N.J.: Wiley-Interscience; 2006.

24. Kirkpatrick LA, Feeney BC. A simple guide to IBM SPSS statistics for version 20.0. Student ed. Belmont, Calif.: Wadsworth, Cengage Learning; 2013.
25. Jensen MP, Chen C, Brugger AM. Interpretation of Visual Analog Scale Ratings \&change scores: A Reanalysis of two clinical trials of postoperative pain. J Pain. 2003;4:407-14.

26. Goldman MP. A comparison of sclerosing agents: clinical \& histologic effects of intravascular sodium morrhuate, ethanolamine oleate, hypertonic saline(11.7\%), and sclerodcx in the dorsal rabbit ear vein. J Dermatol Surg Oncol. 1991;17:354-62.

27. Ahmed WS. Efficacy of Ethanolamine Oleate Sclerotherapy in Treatment of Peripheral Giant Cell Granuloma. Oral maxillofacial Surg J 2016;74:2200-6.

28. Choi YH, Han MH, O-Ki K, Cha SH, Chang KH. Craniofacial cavernous venous malformations; percutaneous sclerotherapy with use of ethanolamine oleate. J Vasc Interv Radiol 2002;13:475-82.

29. Das BK, Hoque S. Treatment of Venous Malformations with Ethanolamine Oleate. Asian J Surg. 2008;31:220-4.

30. Yamamoto K, Sakaguchi H, Anai H, Tanaka T, Morimoto K, Kichikawa K, et al. Sclerotherapy for simple cysts with use of ethanolamine oleate: preliminary experience. Cardiovasc Intervent Radiol 2005;28:751-5.

31. Hedberg SE, Fowler DL, Ryan LR. Injection sclerotherapy of esophageal varices using ethanolamine oleate: a pilot study. Am J Surg 1982;143:426-31.

32. Hooiveld M, Roosendaal G, Wenting M, van den Berg M, Bijlsma J, Lafeber F. Short-term exposure of cartilage to blood results in chondrocyte apoptosis. Am J Pathol 2003;162:943-51.

33. Schultz S. Evaluation of periarticular autotransfusion for therapy of recurrent dislocations of the temporomandibular joint. Dtsch Stomatol 1973;23:94-8.

34. Jacobi-Hermanns E, Tetsch P. Pericapsular autologous blood injection as therapy for habitualtemporomandibular joint luxation. Dtsch Zahnarztl Z 1981;36:187-90.

35. Vasconcelos BC, Porto GG, Lima FT. Treatment of chronic mandibular dislocations using miniplatesfollow-up of 8 cases and literature review. Int J Oral Maxillofac Surg 2009;38:933-6.

36. Anjum S, Faisal M, Nadeem M, Warraich RA. Outcomes of autogenous blood injection in the treatment ofrecurrent dislocation of temporomandibular joint (tmj). Pak Oral Dental J 2013;133:1-16.

37. Triantafillidou K, Venetis G, MarkosA.Short-term results of autologous blood injection for treatment of habitual TMJ luxation. J Craniofac Surg 2012;23:689-92.

38. Bayoumi AM, Al-Sebaei MO, Mohamed KM, Al-Yamani AO, Makrami AM. Arthrocentesis followed by intraarticular autologous blood injection for the treatment of recurrent temporomandibular joint dislocation. Int J Oral Maxillofac Surg. 2014;43:1224-8.

39. Matsumotoa A, Matsumotoa K, Kakimotob N, Yuraaa Y. Arthroscopic findings after autologous blood injection in the treatment of recurrent temporomandibular joint dislocation. J Oral Maxillofac Surg Med Pathol 2015;27:225-7. 